\title{
Marcadores moleculares e descritores morfo-agronômicos na avaliação da diversidade genética de bucha (Luffa cylindrica)
}

Ariel Dotto Blind ${ }^{1}$, Fabiola Viana Almeida Almeida ${ }^{2}$, Magno Savio Ferreira Valente ${ }^{3}$, Pedro de Queiroz Costa Neto ${ }^{4}$, Maria Teresa Gomes Lopes ${ }^{4}$, Danilo Fernandes Silva Filho ${ }^{1}$

${ }^{1}$ Instituto Nacional de Pesquisa da Amazônia - INPA, Departamento de Agronomia, Fitotecnia em Horticultura, Manaus, AM. ${ }^{2}$ Universidade do Estado do Amazonas - UEA, AM. ${ }^{3}$ Instituto Federal do Amazonas - IFAM, AM. ${ }^{4}$ Universidade Federal do Amazonas - UFAM, AM. E-mail: ariel.blind@inpa.gov.br

\section{Resumo}

O estudo da diversidade de Luffa cylindrica pode permitir triagens específicas para diferentes aplicações, visando uso e o melhoramento da espécie. Dados moleculares e de trinta descritores morfo-agronômicos foram utilizados em análises multivariadas na caracterização de 24 acessos de bucha provenientes de sete Estados brasileiros. Os resultados obtidos demonstraram que os acessos em estudo possuem ampla variabilidade potencial para todos os caracteres morfo-agronômicos analisados. Os caracteres que mais contribuíram para a divergência entre os acessos foram o comprimento dos frutos $(62,32 \%)$ e a circunferência apical dos frutos (19,70\%). Marcadores AFLP foram eficientes em agrupar os acessos de bucha provenientes de diferentes regiões brasileiras e apresentaram $66,8 \%$ de polimorfismo. 0 agrupamento obtido a partir da análise conjunta dos dados moleculares e morfo-agronômicos separou os acessos em quatro grupos e foi concordante com a análise bayesiana de agrupamento na separação dos acessos coletados no Norte com aqueles prospectados nas demais regiões brasileiras.

Palavras-chave: Análise multivariada; estrutura genética; polimorfismo; recursos genéticos.

\section{Molecular markers and morpho-agronomic descriptors in the assessment genetic diversity of bucha (Luffa cylindrica)}

\begin{abstract}
The study of the diversity of Luffa cylindrica may allow specific screening for different applications, aiming at the use and improvement of the species. Molecular data and thirty morpho-agronomic descriptors were used in multivariate analyzes to characterize 24 bushing accessions from seven Brazilian states. The results showed that the accessions under study have a wide potential variability for all the morpho-agronomic characters analyzed. The characters that most contributed to the divergence between the accessions were the fruit length (62.32\%) and the apical circumference of the fruits (19.70\%). AFLP markers were efficient in grouping the bushing access from different Brazilian regions and showed $66.8 \%$ of polymorphism. The clustering obtained from the joint analysis of molecular and morpho-agronomic data separated the accessions into four groups and was consistent with the Bayesian cluster analysis in the separation of accessions collected in the North with those prospected in the other Brazilian regions.
\end{abstract}

Keywords: Multivariate analysis; genetic structure; polymorphism; genetic resources.

\section{Introdução}

O comércio mundial de fibras naturais tem ganhado impulso nos últimos anos em virtude do apelo ambiental acerca da aplicação em matrizes e compósitos biodegradáveis (GHALI et al., 2011) e pela sua ampla aplicabilidade em diversas áreas da engenharia $(\mathrm{OBOH}$; $A L U Y O R$, 2009). A bucha vegetal (Luffa cylindrica) tem como principal atrativo as fibras lignocelulósicas biodegradáveis atóxicas quando não tratadas, além de ser um recurso natural renovável que proporciona custo relativamente baixo de 
produção (TANOBE et al., 2014). Apesar de não possuir a mesma importância comercial de outras representantes da família das cucurbitáceas, a bucha vegetal é comumente utilizada na limpeza geral, higiene pessoal, confecção de artesanatos e na indústria como filtros para piscinas, água e óleo. No entanto, L. cylindrica constitui importante recurso vegetal ainda subutilizado no Brasil, mas com grande potencial de uso e demanda em diversos setores do país.

A bucha possui origem apontada em regiões tropicais da Ásia e está dispersa em diversos territórios, incluindo de norte a sul do Brasil (BISOGNIN, 2002). No território brasileiro é possivel observar considerável variabilidade morfo-agronômica da espécie, com indivíduos apresentando ampla variação em caracteres relacionados à conformação das ramas, do fruto, das sementes e da fibra (JOSHI et al., 2010).

A importância econômica da bucha não está presente somente em seus frutos, diferentes estruturas vegetativas têm sido indicadas para o tratamento de um amplo espectro de enfermidades, incluindo picadas de cobra, convulsões, câimbras, tétano, bronquite crônica, asma, sinusite e como anti-inflamatório (PARTAP et al., 2012). Além do seu uso medicinal, as pesquisas atualmente conduzidas com a espécie avaliam principalmente as propriedades térmicas, mecânicas e químicas de suas fibras (GHALl et al., 2011; TANOBE et al., 2014). São poucos os trabalhos que geram conhecimento da variação genética em espécies do gênero (TYAGI et al., 2015), havendo a necessidade de estudos sobre a diversidade genética em acessos distanciados geograficamente, o que iria auxiliar na descoberta de possíveis amostras com potencial diferenciado para a agroindústria e fontes de genes de interesse para programas de melhoramento (PRAKASH et al., 2014).

A determinação da diversidade genética entre indivíduos ou grupos de indivíduos pode ser obtida por métodos específicos de acordo com o tipo de informação coletada ou através da análise conjunta, com avaliação simultânea dos dados provenientes de marcadores moleculares e aqueles obtidos na avaliação de caracteres morfo-agronômicos (MOURA et al., 2010). Adicionalmente, técnicas de análise multivariada permitem reunir múltiplas informações descritivas das plantas e, aliado ao conhecimento de diversidade genética, atua como guia para a escolha de caracteres mais eficientes na discriminação e determinação dos genótipos mais promissores para a exploração comercial (CRUZ et al., 2012; SILVA et al., 2012).

Deste modo, o presente estudo teve por objetivo caracterizar a diversidade e estrutura genética entre acessos de bucha presentes em diferentes regiões do Brasil, por meio da análise de marcadores AFLP e descritores morfoagronômicos.

\section{Material e Métodos}

Um total de 24 acessos de bucha provenientes de sete Estados brasileiros foram cultivados na estação experimental de Hortaliças do Instituto Nacional de Pesquisas da Amazônia, localizada na cidade de Manaus-AM, em dezembro de 2013 (Tabela 1).

Tabela 1. Lista dos acessos de Luffa cilyndrica e seus respectivos locais de coleta. Manaus, AM. 2016.

\begin{tabular}{cccccc}
\hline Acesso* & BAG $^{1}$ & Local & Acesso* $^{*}$ & BAG $^{1}$ & Local \\
\hline 1 & FBVAR-15 & São José - SC & 13 & IAC-86 & Campinas - SP \\
2 & FBVAR-44 & Tomé Açu - PA & 14 & IAC-82 & Campinas - SP \\
3 & FBVAR-20 & Palotina - PR & 15 & IAC-9 & Brasília - DF \\
4 & IAC-9 & Monte Alegre do Sul - SP & 16 & FBVAR-06 & Presidente Figueiredo - AM \\
5 & IAC-27 & Umuarama - PR & 17 & FBVAR-13 & Manacapuru - AM \\
6 & IAC-30 & Campinas - SP & 18 & FBVAR-19 & Manaus - AM \\
7 & IAC-42 & Presidente Prudente - SP & 19 & FBVAR-34 & Iranduba - AM \\
8 & IAC-12 & Campinas - SP & 20 & FBVAR-03 & Presidente Figueiredo - AM \\
9 & IAC-92 & Eldorado - SP & 21 & FBVAR-10 & Porto Velho - RO \\
10 & IAC-20 & Umuarama - PR & 22 & FBVAR-28 & Porto Velho - RO \\
11 & IAC-47 & Monte Alegre do Sul - SP & 23 & FBVAR-29 & Manaus - AM \\
12 & IAC-55 & Brasília - DF & 24 & FBVAR-07 & Vilhena - RO \\
\hline
\end{tabular}

* Numeração utilizada para identificação no estudo proposto

${ }^{1}$ Identificação no BAG - Banco Ativo de Germoplasma 
O delineamento experimental utilizado foi o de blocos casualizados com 4 repetições e três plantas por parcela. O experimento foi conduzido em condições de campo no sistema de cultivo de espaldeira com espaçamento de $3,0 \mathrm{~m}$ $x 1,5 \mathrm{~m}$ entre plantas e entre linhas. 0 solo do local foi classificado como Argissolo Amarelo distrófico de textura arenosa e recebeu preparo convencional de cultivo para cucurbitáceas.

Folhas jovens e sadias de cada acesso foram usadas para extração de DNA de acordo como protocolo CTAB descrito por Doyle e Doyle (1997). Após a quantificação do DNA feita em gel de agarose $1 \%$, as amostras foram diluídas em água ultrapura para ajustar as suas concentrações para condição de trabalho (10 $\mathrm{ng} / \mu \mathrm{L})$.

A análise por marcadores AFLP foi realizada segundo os procedimentos propostos por Vos et al. (1995), com modificações de Lopes et al. (2003). Para as reações de digestão do DNA foi utilizada a combinação de enzimas de restrição EcoRI/Msel. Na reação de préamplificação, utilizou-se 3 amostras aleatórias dos acessos combinadas com oito pares de iniciadores, testados com base no polimorfismo apresentado por Priori et al. (2013) em Cucurbita pepo, para ajuizar a qualidade de amplificação e o número de locos polimórficos amplificados. As sequências dos oligonucleotídeos usados na reação de pré-amplificação foram: $\mathrm{E} / \mathrm{AAC}+\mathrm{M} / \mathrm{CTC}, \quad \mathrm{E} / \mathrm{AGC}+\mathrm{M} / \mathrm{CTC}, \mathrm{E} / \mathrm{ATC}+\mathrm{M} / \mathrm{CTC}$, $\mathrm{E} / \mathrm{AGT}+\mathrm{M} / \mathrm{CAT}, \quad \mathrm{E} / \mathrm{ACC}+\mathrm{M} / \mathrm{CTC}, \mathrm{E} / \mathrm{ACC}+\mathrm{M} / \mathrm{CTC}$, $E / A C T+M / C A T$ e $E / A C A+M / C A T$. Nas reações de amplificação seletiva, cada amostra foi aplicada na cuba de eletroforese vertical em gel de poliacrilamida $6 \%$ (acrilamida/bis-acrilamida $(19: 1 \mathrm{v} / \mathrm{v}))$ sob potência constante de $80 \mathrm{~W}$ durante duas horas e meia. Para a revelação do gel, usou-se o método de coloração com nitrato de prata segundo o protocolo proposto por Creste et al. (2001).

A partir da leitura cuidadosa dos géis de poliacrilamida foi construída uma matriz binária em que zero e um indicaram ausência e presença de fragmentos, respectivamente. Com base no polimorfismo detectado a partir dos marcadores AFLP, o programa Structure v.2.4. (PRITCHARD et al., 2000) foi utilizado para atribuir indivíduos a um número $\mathrm{K}$ de agrupamentos com base em uma abordagem Bayesiana. Para realização das análises de estrutura genética, foi considerado o modelo de mistura com frequências correlacionadas e valores de agrupamento (K) variando de 1 a 10 com cinco repetições para cada valor de $\mathrm{K}$ testado. $\mathrm{O}$ número de interações utilizadas no burn-in e MCMC (Markov Chain Monte Carlo) foram de 100.000 e 200.000, respectivamente. A determinação do valor mais provável de $\mathrm{K}$ foi tomada segundo o critério $\Delta \mathrm{K}$ descrito por Evanno et al. (2005) e o método IPlateau descrito por Viana et al. (2013).

Na caracterização morfo-agronômica dos 24 acessos de bucha, foram utilizados 30 descritores, sendo 22 qualitativos e 8 quantitativos. Parte da caracterização dos acessos desenvolveu-se por meio de descritores botânicos extraídos e adaptados do "Descriptors for Sponge Gourd [Luffa cylindrica (L.) Roem.]" conforme sugestão de Joshi et al. (2014) para caracteres de fácil mensuração e variabilidade de expressão. Ao todo foram considerados 22 caracteres envolvendo as estruturas da rama, do fruto, da semente e da fibra dos acessos, sendo estes avaliados no início da colheita em todas as plantas das parcelas no quarto mês póstransplante. Os descritores qualitativos utilizados foram: tamanho de folhas, potencial de ramificação, posição da inflorescência, margem da folha, formato da folha, expressão sexual, cor da flor, raiz adventícia, cor do fruto maturo, tamanho do pedúnculo, tipo de fruto, casca do fruto, formato apical do fruto, formato basal do fruto, forma do fruto, número de locos, cor da semente, tamanho da semente, formato da semente, tipo da semente, cor natural da fibra e maciez da fibra.

Para os descritores quantitativos relacionados à produção, foram tomados os dados obtidos em cada colheita considerando 6 meses de produção. As variáveis de produção avaliadas foram: número médio de frutos ( $n$ ), massa seca da fibra do fruto $(\mathrm{g})$, comprimento do fruto $(\mathrm{cm})$, circunferência apical do fruto $(\mathrm{mm})$, circunferência medial do fruto $(\mathrm{mm})$, circunferência basal do fruto $(\mathrm{mm})$, espessura mínima da fibra $(\mathrm{mm})$ e espessura máxima da fibra $(\mathrm{mm})$. A importância relativa dos caracteres, baseando-se no método proposto por Singh (1981), foi aplicada aos dados quantitativos por meio do aplicativo computacional em genética e estatística, Programa Genes, versão 2014.6.1 (CRUZ, 2013).

Visando complementar o estudo de divergência genética dos acessos de bucha, foi considerada a análise conjunta dos dados 
moleculares, multicategóricos e quantitativos por meio da proposta de Gower (1971). O algoritmo de Gower é expresso por: $S_{i j k}=\frac{\sum_{k=1}^{v} W_{i j k} S_{i j k}}{\sum_{k=1}^{v} w_{i j k}}$. Onde: $\mathrm{K}=$ é o número de variáveis $(\mathrm{K}=1,2, \ldots, \mathrm{v})$; $\mathrm{i}$ e $\mathrm{j}=$ são dois indivíduos que representam $\mathrm{o}$ acesso; $W_{\mathrm{ijk}}=$ peso dado a comparação ijk, atribuindo valor 1 para comparações válidas e valor 0 para comparações inválidas (quando o valor da variável está ausente em um ou ambos indivíduos); $\mathrm{S}_{\mathrm{ijk}}=$ contribuição da variável $\mathrm{K}$ na similaridade entre os indivíduos i e $\mathrm{j}$, com valores entre 0 e 1 . Para características binárias, a similaridade é obtida pelo grau de coincidência de padrão "1-1", assumindo peso $\left(\mathrm{W}_{\mathrm{ijk}}\right)$ nulo nas situações em que um padrão fenotípico não se manifesta em ambos os indivíduos, para a késima variável. Assim, quando é analisado somente variáveis binárias, esse coeficiente é igual ao proposto pelo índice de Jaccard. Para variável qualitativa (nominal), o valor da variável $\mathrm{K}$ é o mesmo para ambos os indivíduos, $\mathrm{i}$ e $\mathrm{j}$, então $S_{\mathrm{ijk}}=1$, caso contrário, é igual a 0; para uma variável quantitativa (contínua) $S_{i j k}=1-\left|Y_{i k}-Y_{j k}\right| / R_{k}$, onde $Y_{i k}$ e $Y_{j k}$ são os valores da variável $K$ para os indivíduos $i$ e $j$, respectivamente, e $R_{k}$ é o intervalo (valor máximo menos o valor mínimo) da variável $k$ na amostra. A divisão por $R_{k}$ elimina as diferenças entre escalas das variáveis, produzindo um valor dentro do intervalo $(0,1)$ e pesos iguais. Posteriormente a matriz de similaridade obtida é convertida em uma matriz de dissimilaridade por meio de seus complementos aritméticos.

Após a obtenção da matriz de distâncias genéticas entre os acessos de $L$. cylindrica considerando a análise conjunta dos dados, foi usado o método hierárquico UPGMA (Unweighted Pair-Group Method Using Arithmetic Average) para visualização da diferenciação genética. A matriz de dissimilaridade e o dendrograma foram obtidos com o auxílio do software estatístico $R$ ( $R$ Development Core Team, 2013). O mesmo software também foi empregado para gerar a matriz dos valores cofenéticos e testar a adequação da análise de agrupamento aos dados originais por meio do pacote Vegan (OKSANEN et al., 2013).

\section{Resultados e Discussão}

Foram testadas oito combinações de oligonucleotídeos em testes de pré-amplificação, das quais serviu como parâmetro na seleção dos quatro iniciadores mais informativos empregados no estudo de todos os indivíduos (Tabela 2).

Tabela 2. Polimorfismo obtido em acessos de Luffa cylindrica a partir de quatro combinações de oligonucleotídeos utilizando marcadores AFLP. Manaus, AM. 2016.

\begin{tabular}{ccccc}
$\begin{array}{c}\text { Combinações de } \\
\text { oligonucleotídeos }\end{array}$ & Total de locos & $\begin{array}{c}\text { Locos } \\
\text { Polimórficos }\end{array}$ & Polimorfismo (\%) & $\begin{array}{c}\text { Gama de } \\
\text { tamanho (bp) }\end{array}$ \\
\hline E+ATC/M+CAT & 55 & 31 & 56,36 & \\
E+AGT/M+CAT & 75 & 56 & 74,67 & $50-500$ \\
E+AAC/M+CTC & 56 & 40 & 71,43 & \\
E+ACA/M+CAT & 55 & 34 & 61,81 & - \\
\hline Total & 241 & 161 & 66,80 & \\
\hline
\end{tabular}

O número de marcas polimórficas por iniciador variou de 31 a 56 e a combinação $\mathrm{E}+\mathrm{AGT} / \mathrm{M}+\mathrm{CAT}$ foi a que produziu o maior número de fragmentos contáveis e informativos. Um total de 241 locos foram detectados, sendo destes, 161 (66,80\%) locos polimórficos. O polimorfismo obtido é comparável ao observado por Tyagi et al. (2015) a partir de marcadores SRAP em 45 acessos de $L$. cylindrica presentes em diferentes regiões geográficas da Índia $(72,8 \%)$, todavia, sensivelmente menor ao detectado por
Prakash et al. (2014) avaliando a diversidade genética de 37 acessos selvagens do gênero Luffa. Estes últimos autores obtiveram 97,3\% de polimorfimo usando marcadores dominantes ISSR.

Para determinar os padrões genéticos de diferenciação e sub estruturação populacional, foi feita a análise bayesiana de agrupamento pelo software Structure (Figura 1). 
Figura 1. Estrutura populacional empregando o software Structure a partir de 24 acessos de Luffa cylindrica para diferentes valores de agrupamento (K). INPA, Manaus, AM. 2016.

\begin{tabular}{lllllllllllllllllllllllll}
\hline Acessos & 1 & 2 & 3 & 4 & 5 & 6 & 7 & 8 & 9 & 10 & 11 & 12 & 13 & 14 & 15 & 16 & 17 & 18 & 19 & 20 & 21 & 22 & 23 & 24 \\
$\mathrm{~K}=2$ & \\
$\mathrm{~K}=3$ & \\
$\mathrm{~K}=4$ &
\end{tabular}

$\mathrm{O}$ critério $\Delta \mathrm{K}$ descrito por Evanno et al. (2005) apontou $K=2$ como o número mais provável de agrupamentos. Este resultado corrobora com a ideia de que os acessos 15 e 17 terem origem compartilhada, sendo resultado de um intercâmbio de genes entre as regiões analisadas. No entanto, o método Iplateau (VIANA et al., 2013) indica que o número mais provável de agrupamentos é $\mathrm{K}=3$, neste caso, os acessos 15 e 17 formariam um grupo independente, com origem não compartilhada com os demais acessos. Independentemente do número de grupos considerados, observa-se a tendência da separação dos acessos coletados no Norte com aqueles prospectados nas demais regiões brasileiras.

É importante salientarmos a importância da caracterização destes acessos não só pelos marcadores moleculares, mas também pelos descritores morfo-agronômicos, uma vez que ambos podem ser complementares quando há interesse em realizar seleção de material a ser submetido a programas de melhoramento genético ou mesmo para discriminação, identificação e caracterização de materiais potenciais para serem designados como variedades (ANDRADE et al., 2011). Na tabela 3 são apresentados os descritores morfológicos observados entre os acessos de bucha. 
Tabela 3. Caracterização de 24 acessos de Luffa cylindrica, considerando análise de 22 descritores morfológicos. Manaus, AM. 2016.

\begin{tabular}{|c|c|c|c|c|c|c|c|c|c|c|c|}
\hline \multirow{2}{*}{ Acessos } & \multicolumn{11}{|c|}{ Descritores } \\
\hline & TF & PR & PI & MF & FF & ES & CF & RA & CFM & TP & TFr \\
\hline 1 & pequena & baixo & intermediária & dentada & orbicular & monoica & amarela & ausente & verde pintalgado & pequeno & cilíndrico \\
\hline 2 & média & média & pendular & dentada & orbicular & monoica & laranja & ausente & verde uniforme & médio & achatado \\
\hline 3 & média & baixo & ereta & dentada & orbicular & hermafrodita & amarela & ausente & verde uniforme & pequeno & cilíndrico \\
\hline 4 & grande & média & intermediária & lisa & oval & monoica & amarelo claro & ausente & verde pintalgado & grande & cilíndrico \\
\hline 5 & média & média & ereta & lisa & orbicular & monoica & amarelo claro & ausente & verde pintalgado & pequeno & cilíndrico \\
\hline 6 & média & alta & ereta & lisa & orbicular & monoica & amarelo claro & ausente & verde pintalgado & médio & cilíndrico \\
\hline 7 & grande & média & pendular & dentada & reniforme & monoica & amarelo claro & ausente & verde pintalgado & pequeno & cilíndrico \\
\hline 8 & grande & média & intermediria & lisa & orbicular & monoica & amarelo claro & ausente & verde uniforme & médio & cilíndrico \\
\hline 9 & grande & alta & intermediária & lisa & oval & monoica & amarela & presente & verde uniforme & médio & cilíndrico \\
\hline 10 & pequena & baixo & ereta & dentada & oval & monoica & amarela & ausente & verde pintalgado & grande & cilíndrico \\
\hline 11 & grande & média & intermediária & lisa & reniforme & monoica & amarela & ausente & verde uniforme & médio & cilíndrico \\
\hline 12 & grande & média & pendular & lisa & orbicular & monoica & amarela & ausente & verde uniforme & médio & cilíndrico \\
\hline 13 & pequena & alta & ereta & lisa & reniforme & monoica & amarela & presente & verde uniforme & médio & triangular \\
\hline 14 & média & média & intermediária & dentada & orbicular & monoica & amarela & ausente & verde pintalgado & pequeno & triangular \\
\hline 15 & média & baixo & pendular & lisa & orbicular & hermafrodita & amarela & ausente & verde uniforme & pequeno & cilíndrico \\
\hline 16 & média & média & ereta & dentada & reniforme & monoica & amarelo claro & ausente & verde uniforme & grande & cilíndrico \\
\hline 17 & média & média & Intermediária & dentada & reniforme & monoica & amarelo claro & ausente & verde pintalgado & pequeno & cilíndrico \\
\hline 18 & média & alta & intermediária & dentada & reniforme & monoica & amarelo claro & ausente & verde pintalgado & pequeno & cilíndrico \\
\hline 19 & média & alta & intermediária & lisa & reniforme & monoica & amarelo claro & ausente & verde uniforme & grande & cilíndrico \\
\hline 20 & grande & alta & intermediária & dentada & orbicular & monoica & amarelo claro & presente & verde uniforme & médio & cilíndrico \\
\hline 21 & média & alta & pendular & dentada & reniforme & monoica & amarelo claro & presente & verde pintalgado & médio & cilíndrico \\
\hline 22 & média & média & ereta & dentada & oval & monoica & amarelo claro & presente & verde uniforme & médio & cilíndrico \\
\hline 23 & pequena & alta & intermediária & dentada & reniforme & monoica & amarela & presente & verde pintalgado & médio & cilíndrico \\
\hline 24 & grande & alta & pendular & lisa & orbicular & monoica & amarela & ausente & verde pintalgado & médio & triangular \\
\hline cont.. & CFr & FAF & FBF & $\mathrm{FFr}$ & NL & CS & TS & FS & SS & CNF & MFi \\
\hline 1 & rugoso & pontudo & oval & elipsoide & três & preta & grande & piriforme & lisa & cristalina & dura \\
\hline 2 & deprimido & pontudo & oval & alongado & três & preta & pequena & piriforme & intermediária & cristalina & macia \\
\hline 3 & deprimido & pontudo & pontudo & elipsoide & três & preta & média & elipsoide & intermediária & creme & muito dura \\
\hline 4 & liso & pontudo & pontudo & redondo & três & preta & grande & elipsoide & intermediária & cristalina & dura \\
\hline 5 & liso & pontudo & oval & elipsoide & três & preta & grande & elipsoide & lisa & cristalina & dura \\
\hline 6 & liso & oval & oval & piriforme & três & preta & média & elipsoide & lisa & cristalina & dura \\
\hline
\end{tabular}




\begin{tabular}{|c|c|c|c|c|c|c|c|c|c|c|c|}
\hline 7 & liso & pontudo & oval & alongado & três & preta & pequena & elipsoide & intermediária & cristalina & dura \\
\hline 8 & liso & pontudo & oval & alongado & três & preta & média & piriforme & intermediária & cristalina & dura \\
\hline 9 & deprimido & pontudo & pontudo & piriforme & três & branca & grande & elipsoide & lisa & cristalina & muito macia \\
\hline 10 & deprimido & deprimido & deprimido & redondo & três & creme & pequena & elipsoide & lisa & cristalina & macia \\
\hline 11 & deprimido & pontudo & deprimido & piriforme & quatro & cinza & média & elipsoide & lisa & cristalina & muito dura \\
\hline 12 & deprimido & pontudo & pontudo & piriforme & três & cinza & média & elipsoide & lisa & cristalina & dura \\
\hline 13 & deprimido & deprimido & deprimido & elipsoide & três & branca & grande & elipsoide & lisa & cristalina & macia \\
\hline 14 & deprimido & oval & oval & elipsoide & três & preta & média & elipsoide & intermediária & creme & macia \\
\hline 15 & liso & deprimido & oval & alongado & três & preta & pequena & oval & intermediária & creme & muito dura \\
\hline 16 & deprimido & deprimido & deprimido & redondo & quatro & preta & média & piriforme & intermediária & amarela & macia \\
\hline 17 & deprimido & pontudo & deprimido & elipsoide & três & preta & pequena & elipsoide & intermediária & cristalina & macia \\
\hline 18 & deprimido & deprimido & pontudo & piriforme & três & preta & média & elipsoide & rugosa & amarela & macia \\
\hline 19 & liso & pontudo & pontudo & elipsoide & três & branca & grande & elipsoide & intermediária & cristalina & muito macia \\
\hline 20 & liso & pontudo & pontudo & piriforme & três & preta & média & piriforme & lisa & cristalina & macia \\
\hline 21 & liso & oval & pontudo & piriforme & três & cinza & média & elipsoide & intermediária & cristalina & macia \\
\hline 22 & liso & pontudo & pontudo & elipsoide & três & preta & pequena & elipsoide & intermediária & cristalina & macia \\
\hline 23 & liso & deprimido & pontudo & elipsoide & três & branca & grande & elipsoide & lisa & cristalina & macia \\
\hline 24 & liso & deprimido & pontudo & alongado & três & preta & grande & elipsoide & lisa & cristalina & dura \\
\hline
\end{tabular}

Raiz Adventícia; CFM = Cor do Fruto Maturo; TP = Tamanho do Pedúnculo; TFr = Tipo de Fruto; CFr = Casca do Fruto; FAF = Formato Apical do Fruto; FBF = Formato Basal do Fruto; $\mathbf{F F r}=$ Forma do Fruto; NL = Número de Locos; $\mathbf{C S}=$ Cor da Semente; $\mathbf{T S}=$ Tamanho da Semente; FS = Formato da Semente; SS = Superfície da Semente; $\mathbf{C N F}=$ Cor Natural da Fibra; MFi = Maciez da Fibra. 
Este conhecimento permite a adoção quase que imediata de acessos com características de interesse por parte dos produtores e são informações úteis para o melhoramento e conservação da espécie.

Os dados morfológicos mostram que, em geral, os materiais analisados possuem diferenças fenotípicas marcantes, dentre elas cita-se a expressão sexual (ES), forma do fruto (FFr) e cor da semente (CS), características estas consideradas de baixa interação ambiental (JOSHI et al., 2014). Os acessos 3 e 15, apresentaram flores masculinas e femininas na mesma haste, 0 que é raro, pois para bucha é relatado praticamente monoecíssimo (JOSHI et al., 2010). Considerando a $\mathrm{FFr}$, os acessos $2,7,8,15$ e 24 mostraram-se com frutos alongados relativamente grandes quando conferidos pelo comprimento. A cor das sementes de bucha é geralmente preta como verificado para a maioria dos acessos estudados (Tabela 3), contudo, os materiais 9, 13, 19 e 23 produzem sementes brancas enquanto que os acessos 11,12 e 21 produzem sementes de coloração cinza e o acesso 10, único a produzir sementes de cor creme. A diferença fenotípica entre plantas alógamas está muitas vezes relacionada com sua genealogia e apesar da bucha possuir baixa depressão por endogamia (QUEIROZ, 2004), é relatado em diversos estudos a influência do modo de conservação do germoplasma entre agricultores, instituições e sua interdependência de expressão com o ambiente (JOSHI et al., 2010).

Uma característica considerada para avaliação após o desenvolvimento das plantas foi a presença de raízes adventícias. A manifestação de raiz adventícia inserida na axila foliar sentido solo foi mais frequente em acessos oriundos da região norte; $20,21,22$ e 23 , contudo, os acessos 9 e 13 também desenvolveram esta estrutura que por sinal é funcional e pode ter relação bem mais específica do que uma simples segregação varietal e sim uma estrutura de adaptabilidade. $\mathrm{Na}$ região norte, além do solo ser pobre nutricionalmente, em diversos municípios os setores agrícolas permanecem com 0 solo bastante úmido e até encharcado, o que pode ter levado a surgir tal adaptação, tanto para extração nutricional como também para aeração radicular. Porém, ainda não há relatos específicos explicando a presença e a funcionalidade dessas raízes em bucha, curiosamente com até 1,5 metros da axila foliar até o solo.

Observa-se que tanto no Brasil como na Ásia, as características relacionadas ao fruto e fibra coincidem com a preferência e hábito cultural dos agricultores do país, haja visto que em determinados locais a escolha de plantio e uso é determinada apenas pela forma do fruto, cor e maciez da fibra (JOSHI et al., 2014). Em contrapartida, para uso industrial, independente do país, existe forte interesse nas análises físicas e mecânicas nas fibras, além de alta produtividade (GHALI et al., 2011).

Caracteres de produção também foram avaliados e a contribuição destes para a divergência genética total observada foi analisada pela estatística (S.j) proposta por Singh (1981), (Tabela 4).

Tabela 4. Contribuição relativa de oito caracteres morfológicos quantitativos para divergência entre 24 acessos de Luffa cylindrica, pela estatística (S.j) proposta por Singh (1981). Manaus, AM. 2016.

\begin{tabular}{lcc}
\hline Caractere & S.j & Contribuição relativa (\%) \\
\hline Comprimento dos Frutos & 82402,59 & 62,32 \\
Circunferência Apical dos Frutos & 26053,59 & 19,70 \\
Circunferência Basal dos Frutos & 8413,392 & 6,36 \\
Espessura Máxima da Fibra & 7389,476 & 5,59 \\
Espessura Mínima da Fibra & 4672,476 & 3,53 \\
Massa Seca dos Frutos & 2143,945 & 1,62 \\
Número Médio de Frutos & 888,0589 & 0,67 \\
Circunferência Mediana dos Frutos & 261,3497 & 0,20 \\
\hline
\end{tabular}

Verificou-se que o caractere comprimento dos frutos exerceu maior influência na divergência entre os acessos (62,32\%), seguida pela circunferência apical dos frutos $(19,70 \%)$, circunferência basal dos frutos $(6,36 \%)$ e espessura máxima da fibra $(5,59 \%)$. O caractere 
que obteve a menor contribuição foi a circunferência mediana dos frutos $(0,20 \%)$. Aliado a maior produtividade e demanda do setor de cosméticos e de limpeza, que tem preferência por plantas com frutos de menor circunferência, com fibras cristalinas, macias e com espessura admissível entre 5 e $10 \mathrm{~mm}$, os acessos 2, 4, 7, $10,13,17,19$ e 23 apresentam maior conjunto de características desejáveis para constituírem-se em variedades.

As semelhanças parentais entre os acessos de bucha foram evidenciadas pela formação e proximidade entre os grupos obtidos pelo método UPGMA (Figura 2).

Figura 2. Dendrograma representativo da divergência genética entre 24 acessos de Luffa cylindrica, obtido pelo método UPGMA, utilizando o algoritmo de Gower como medida de dissimilaridade. Coeficiente de correlação cofenética: $r=0,9606$. A linha horizontal tracejada representa o corte estimado pelo método de Mojena (1977). INPA, Manaus, AM. 2016.

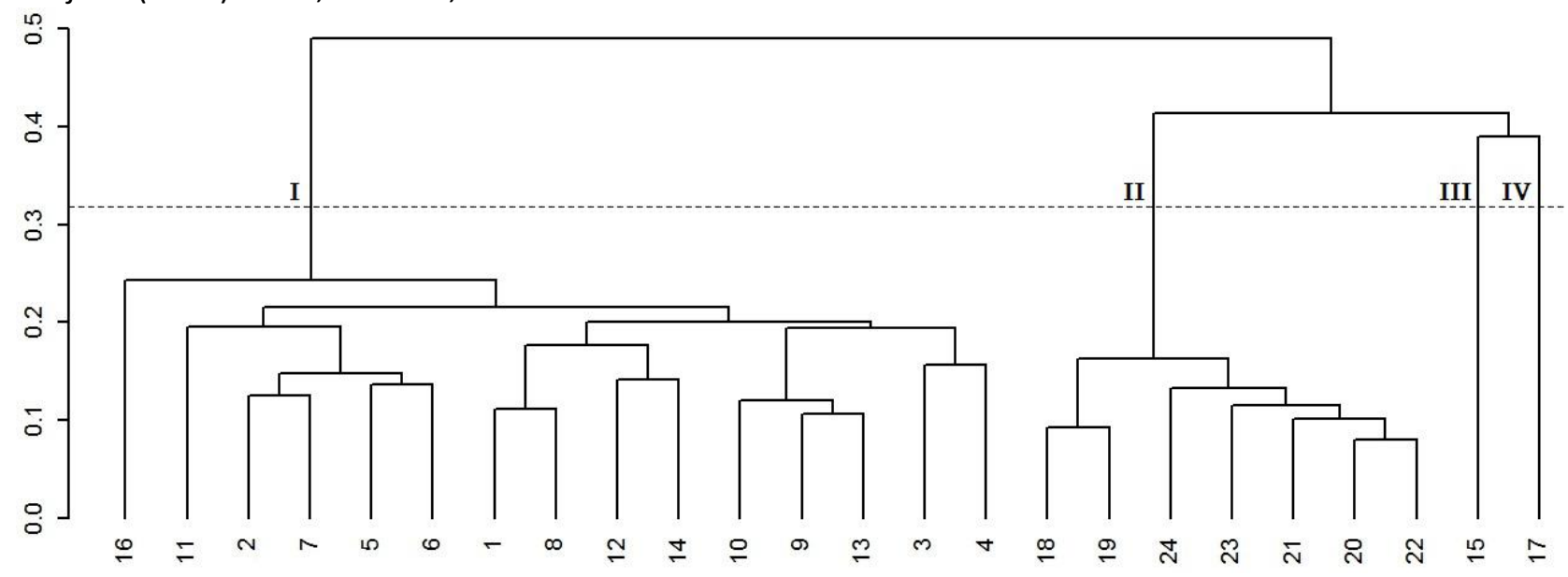

A análise conjunta sobre os dados moleculares, morfológicos qualitativos e quantitativos permitiu a unificação de todas as informações em uma figura, constituindo-se em alternativa viável e ferramenta importante para o conhecimento da divergência genética entre os acessos (MOURA et al., 2010). É importante destacar que o coeficiente de correlação cofenética $(r=0,96)$ indicou bom ajuste da representação simplificada da matriz de distâncias genéticas por meio do dendrograma.

Observa-se a formação de quatro grupos distintos, indicando uma diferenciação genética entre os acessos coletados na região norte, com aqueles oriundos das regiões sul, sudeste e centro-oeste do Brasil, corroborando com a análise bayesiana de agrupamento. As exceções foram os acessos 2, 15 e 16. Os acessos 2 e 16 foram incluídos no agrupamento $\mathrm{I}$, enquanto $\mathrm{O}$ acesso 15 foi alocado em um agrupamento mais próximo daqueles acessos coletados na região norte, ou seja, mais próximo do grupo II. Isto pode ter ocorrido devido a dispersão e fluxo de cultivo, pois no Brasil a bucha é cultivada de forma incipiente, sem triagem específica para uso de acessos e/ou variedades, além de ser uma espécie de polinização cruzada. Estas considerações se assemelham ao relatado por Zhang et al. (2008) e Silva et al. (2012) ao verificarem alto grau de parentesco entre acessos de bucha presentes em diferentes regiões da Ásia.

Analisando a procedência dos materiais e a caracterização molecular e morfo-agronômica dos mesmos, fica evidente a existência de alta variabilidade fenotípica para maioria dos caracteres analisados e apesar da distância geográfica não permitir generalizações sobre a diversidade genética da bucha, neste estudo, é notório o distanciamento genético dos acessos presentes na região norte do país com os demais acessos. Os resultados apresentados pela análise conjunta foram semelhantes aos obtidos utilizando apenas os dados moleculares. Assim, o uso dos marcadores moleculares torna-se importante na manutenção da identidade genética de materiais promissores. No entanto, a caracterização morfológica ajuda na elaboração das relações filogenéticas entre espécies silvestres do gênero (PRAKASH et al., 2013) e torna-se ainda mais interessante quando se tem necessidade de avaliar características desejáveis 
pelo mercado agroindustrial, como aspectos relacionados à produção dos frutos e qualidade da fibra da bucha, ou ainda interessantes para o produtor, como potencialidade de ramificação e uniformidade produtiva. É importante destacarmos que este é o primeiro estudo de diversidade genética que agrega informações fenotípicas e moleculares de acessos de bucha coletados no Brasil, contribuindo para conservação e utilização da espécie.

\section{Agradecimentos}

À Fundação de Amparo à Pesquisa do Estado do Amazonas (FAPEAM) pelo auxílio financeiro.

\section{Referências}

ANDRADE, R. A.; WICKERT, E.; MARTINS, A. B. G.; ANDRADE, M. M. C.; LEMOS, E. G. M. Diversidade genética de acessos de Nephelium lappaceum L: através de caracterização morfológica e molecular. ComunicataScientiae, v. 29, n. 2, p. 91-99, 2011.

BISOGNIN, D. A. Origin and evolution of cultivated cucurbits. Ciência Rural, Santa Maria, v. 32, n. 4, p. 715-723, 2002.

https://doi.org/10.1590/S0103-

\section{8}

CRESTE, S.; TULMANN, N. A.; FIGUEIRA, A. Detection of single sequence repeat polymorphisms in denaturing polyacrilamide sequencing gels by silvers taining. Plant Molecular Biology Reporter, v. 19, n. 4, p. 299306, 2001. https://doi.org/10.1007/BF02772828

CRUZ, C. D. Genes: a software package for analysis in experimental statistics and quantitative genetics. Acta Scientiarum, v. 35, n. 3, p. 271-276, 2013.

http://dx.doi.org/10.4025/actasciagron.v35i3.212 $\underline{51}$

CRUZ; C. D.; REGAZZI, A. J.; CARNEIRO, P. C. S. Modelos biométricos aplicados ao melhoramento genético. 4.ed. Viçosa: Editora UFV, 2012. 514 p. v.1.

DOYLE, J. J.; DOYLE, J. L. Isolation of plant DNA from fresh tissue. Focus, v. 12, n. 1, p. 13-15, 1997.
EVANNO, G.; REGNAUT, S.; GOUDET, J. Detecting the number of clusters of individuals using the software STRUCTURE: a. Molecular Ecology, $v$. 14, n. 8, p. 2611-2620, 2005.

http://dx.doi.org/10.1111/i.1365294X.2005.02553

GHALI, L. H.; ALOUI, M.; ZIDI, M.; DALY, H. B.; MSAHLI, S.; SAKLI, F. Effect of chemical modification of Luffa cylindrica fiber son the mechanical and hygro termal behaviours of polyester/luffa composites. Bio Resources, v. 6, n. 4, p. 3836-3849, 2011.

GOWER, J. C. A general coefficient of similarity and some of its properties. Biometrics, v. 27, n. 4, p. 857-874, 1971.

https://doi.org/10.2307/2528823

JOSHI, B. K.; UPADHYAY, M. P.; BANIYA, B. K.; DONGOL, D. M.; TIWARI, R. K.; SHRESTHA, P. Evaluation of sponge gourd landraces in line with the reliability of names given by farmers. Nepal Journal of Science and Technology, v. 11, p. 9-16, 2010. https://doi.org/10.3126/njst.v11i0.4083

JOSHI, B. K.; KC, H. B.; TIWARI, R. K.; GHALE, M.; STHAPIT, B. R.; UPADHYAY, M. P. Descriptors for sponge gourd (Luffa cylindrica L. Roem). Nepal: NARC: LIBIRD; Roma: IPGRI, 2014. 43 p.

LOPES, R.; LOPES, M. T. G.; FIGUEIRA, A. V. D. O.; CAMARGO, L. E. A.; FUNGARO, M. H. P.; CARNEIRO, M. S.; VIEIRA, M. L. C. Marcadores moleculares dominantes (RAPD e AFLP): aspectos técnicos e interpretação genética. Biotecnologia Ciência e Desenvolvimento, v. 29, p. 64-68, 2003.

MOJENA, R. Hierarchical grouping methods and stopping rules: na evaluation. The Computer Journal, v. 20, n. 4, p. 359-363, 1977.

http://dx.doi.org/10.1093/comjnl/20.4.359

MOURA, M. C. C. L.; GONÇALVES, L. S. A.; SUDRÉ, C. P.; RODRIGUES, R.; AMARAL JÚNIOR, A. T.; PEREIRA, T. N. S. Algoritmo de Gower na estimativa da divergência genética em germoplasma de pimenta. Horticultura Brasileira, v. 28, n. 2, p. 155-161, 2010.

https://doi.org/10.1590/S0102$\underline{05362010000200003}$

$\mathrm{OBOH}$, O.; ALUYOR, E. O. Luffa cylindrica - an emerging cash crop. African Journal of 
Agricultural Research, v. 4, n. 8 , p. 684-688, 2009.

OKSANEN, J.; BLANCHET, F. G.; KINDT, R.; OKSANEN, M. J.; SUGGESTS, M. Vegan: community ecology package version 2.0-10. Helsinki: CRAN, 2013.

PARTAP, S.; KUMAR, A.; SHARMA, N. K.; JHA, K. K. Luffa cylindrica: an important medicinal plant. Journal of Natural Product and Plant Resources, v. 2, n. 1, p. 127-134, 2012.

PRAKASH, K.; PATI, K.; ARYA, L.; PANDEY, A.; ANDVERMA, $M$. Population structure and diversity in cultivated and wild Luffa species. Biochemical Systematics and Ecology, v. 56, p. 165-170, 2014.

http://dx.doi.org/10.1016/i.bse.2014.05.012

PRAKASH, K.; PANDEY, A.; RADHAMANI, J.; BISHT, I. S. Morphological variability in cultivated and wild species of Luffa (Cucurbitaceae) from India. Genetic Resources and Crop Evolution, v. 60, n. 8, p. 2319-2329, 2013.

http://dx.doi.org/10.1007/s10722-013-9999-7

PRIORI, D. BARBIERI, R. L.; CASTRO, C. M.; OLIVEIRA, A. C.; VILELA, J. C. B.; MISTURA, C. C. Diversidade genética de Cucurbita pepo, $C$. argyrosperma e C. ficifolia empregando marcadores microssatélites. Horticultura

Brasileira, v. 31, n. 3, p. 361-368, 2013.

https://doi.org/10.1590/S0102$\underline{05362013000300004}$

PRITCHARD, J. K.; STEPHENS, M.; DONNELLY, P. Inference of population structure using multilocus genotype data. Genetics, v. 155, n. 2, p. 945-959, 2000.

QUEIROZ, M. A. Germplasm of Cucurbitaceae in Brazil. Crop Breeding and Applied Biotechnology, v. 4, n. 4, p. 377-383, 2004.

https://doi.org/10.12702/1984-7033.v04n04a01

R CORE TEAM: a language and environment for statistical computing. Vienna: R Foundation for Statistical Computing, 2015. Disponível em: http://www.R-project.org. Acesso em: 01 jun. 2015.

SILVA, M. W. K. P.; RANIL, R. H. G.; FONSEKA, R. M. Luffa cylindrica (L.) M. Roemer (Sponge
Gourd-Niyanwetakolu): na emerging high potential under utilized Cucurbit. Tropical Agricultural Research, v. 23, n. 2, p. 186-191, 2012. https://doi.org/10.4038/tar.v23i2.4650

SINGH, D. The relative importance of characters affecting genetic divergence. The Indian Journal of Genetic and Plant Breeding, v. 41, p. 237-245, 1981.

TANOBE, V. O.; FLORES-SAHAGUN, T. H.; AMICO, S. C.; MUNIZ, G. I.; SATYANARAYANA, K. G. Sponge Gourd (Luffa cylindrica) reinforced polyester composites: preparation and properties. Defense Science Journal, v. 64, n. 3, p. 273-280, 2014.

http://dx.doi.org/10.14429/dsj.64.7327

TYAGI, R.; SHARMA, V.; SUREJA, A. K.; MUNSHI, A. D.; ARYA, L.; VERMA, M. Deciphering population structure and diversity in Luffa cylindrica (L.) M. Roem. Using morphological and sequence-related amplified polymorphism markers. Plant Genetic Resources: Characterization and Utilization, v. 1, p. 1-4, 2015.

http://dx.doi.org/10.1017/S1479262115000258

VIANA, J. M. S.; VALENTE, M. S. F.; SILVA, F. F.; MUNDIM, G. B.; PAES, G. P. Efficacy of population structure analysis with breeding populations and in bredlines. Genetica, v. 141, n. 7-9, p. 389-399, 2013. http://dx.doi.org/10.1007/s10709-0139738-1

VOS, P.; HOGERS, R.; BLEEKER, M.; REIJANS, M.; LEE, T. V. D.; HORNES, M.; FRITERS, A.; POT, J.; PALEMAN, J.; KUIPER, M.; ZABEAU, M. AFLP: a new technique for DNA fingerprinting. Nucleic acids research, v. 23, n. 21, p. 4407-4414, 1995. http://dx.doi.org/10.1093/nar/23.21.4407

ZHANG, S.; HU, J.; XU, S. Developmental genetic analysis of fruit shape traits under different environmental conditions in sponge gourd (Luffa cylindrical (L) Roem. Violales, Cucurbitaceae). Genetics and Molecular Biology, v. 31, n. 3, p. 704-710, 2008. https://doi.org/10.1590/S141547572008000400017 